\title{
AC 2012-3186: AN INNOVATIVE APPROACH TO THE FUNDAMENTALS OF ENGINEERING COURSE
}

\author{
Mr. Arthur F. Garcia Jr., Palm Beach State College
}

Arthur F. Garcia, Jr., has been teaching on college campuses since 2000. He taught intermediate algebra and trigonometry at Montgomery College in Maryland prior to moving to Florida in 2002. Since the fall of 2002, he has been an Adjunct Instructor at Palm Beach State College, where he began as an instructor of pre-college algebra classes. In addition, he has taught algebra, statistics and a course on entrepreneurship at Northwood University in Palm Beach county (from 2002 to 2005). Since the Fall term of 2005, he has been teaching Introduction to Engineering (EGN 1002) at Palm Beach State College exclusively. After his college graduation in 1966, Garcia had a rewarding career in engineering and in business prior to retiring in early 2000. He used computers extensively throughout his career as a tool for solving engineering problems and for solving business problems as well. In 1986, he founded GCI Information Services, Inc. (originally Garcia Consulting, Inc.), with a staff of only four employees and with the objective of offering specialty engineering services to the Naval Sea Systems Command (U.S. Navy) in Arlington, Va. Over the following 13 years, Garcia expanded his Virginia-based company to offer information services as well as engineering services, which led to a dramatic growth of his company as it met an emerging new demand for information services. As a consequence of this dramatic growth, GCI Information Services received a number of outstanding small business awards including the FastTrack Award in 1996 and 1997 and a Fast 50 Award in 1997. Garcia was a finalist in the Ernst and Young Entrepreneur of the Year Award in 1997 and 1998. Garcia was interviewed as a featured entrepreneur on the Building America television show which aired on CBS in Nov. 1997, and again in June 1998. This program featured fast growing and high technology companies as examples of successful entrepreneurial small businesses. By the end of 1999, GCI Information Services had more than 300 employees in 20 states and an office in London, England. During that year, Garcia had been approached by other companies interested in acquiring GCI Information Services, which led to his selling the company by the end of the year. The acquisition of his company was completed in Jan. 2000, and Garcia retired shortly afterwards. Prior to starting his own business, Garcia had 20 years of engineering experience. He initially worked for the U.S. Department of the Navy upon graduating from college in 1966 and into the 1970s. He wrote extensively on many technical topics and developed a number of computer programs (in Fortran and Basic languages) for designing various mechanical systems for ship propulsion systems and other special mechanical systems, as well. During the energy crisis years of the mid-1970s and early 1980s, he worked on energy research projects for several companies. Garcia was awarded his P.E. license in the state of Maryland in 1984. He received his M.S. degree in mechanical engineering from George Washington University (Washington, D.C.) in 1979. He graduated from the University of Texas (Austin) in 1966 with a B.S. in mechanical engineering. He received his A.A. from San Antonio (Junior) College in 1963 and graduated from Douglas MacArthur High School in San Antonio in 1961. 
An Innovative Approach to the Fundamentals of Engineering Course Arthur F. Garcia, Jr.

Palm Beach State College

Boca Raton, Florida

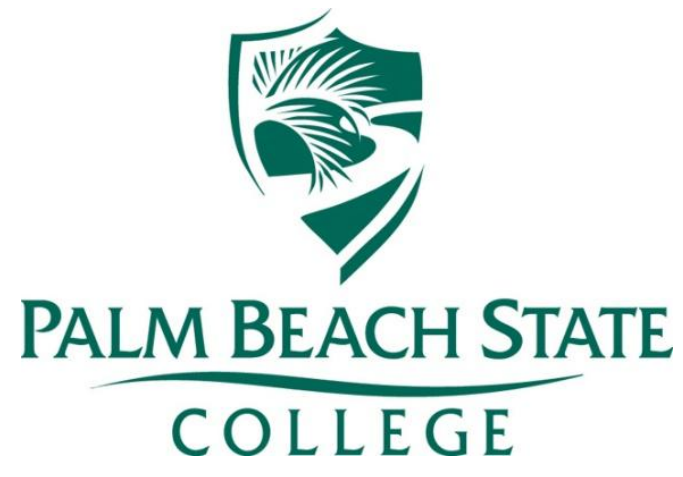


Introduction

For incoming freshman and sophomores, colleges offer a Fundamentals of Engineering course. This course is generally an opportunity to motivate the incoming engineering students to commit to engineering as a career. Most students have some uncertainties in pursuing engineering. Some incoming students are more mature than others and more mentally prepared for the rigor and discipline of engineering courses. However, some students are not as mature but can be inspired to become more serious. With an encouraging preparation in the Fundamentals course, more of the maturing students can be motivated to excel in their junior and senior level courses. With some nurturing, it is possible to engage that deeper latent talent of all ambitious engineering students. The objectives of the course are:

1. to prepare students for their future engineering courses,

2. to introduce students to the various engineering disciplines,

3. to use the electronic spreadsheet as a tool for solving engineering problems, and

4. to prepare students for the business world of engineering.

Most engineering curricula do not include courses on how to use the spreadsheet. The general attitude of engineering faculty is that the spreadsheet is picked up through on-the-job training. However some exposure on how to use a spreadsheet effectively for engineering applications can go a long way to adapting the spreadsheet to more highly sophisticated analyses. Graduating engineers will eventually use specialty software such as finite element analysis with greater confidence when computer applications become second nature to them. The Fundamentals course offers the engineering student an early opportunity to apply the versatile software of the portable computer to realistic analytical applications.

A well-structured Fundamentals course will appeal to the entering student's need to perceive his or her future career in engineering. At Palm Beach State College (PBSC) in Boca Raton, Florida, the Fundamentals course objectives are achieved by:

assigning each student a 10 minute PowerPoint presentation on a "Famous Engineer" and

requiring the use of the electronic spreadsheet as a tool for solving engineering problems.

The Famous Engineer Presentation

As an icebreaker with the first class, students are asked to stand up in turn and introduce themselves to the rest of the class. They are prompted to mention where they went to high school and how they chose engineering. As the instructor, I get a feel for the mix of students. Some are forthright and others are shy. Most have some idea of the engineering field they intend to pursue. In general, my classes are evenly divided between civil, mechanical, electrical and computer engineering interests. My course is designed to expose all students to these fundamental 
engineering disciplines as well as aerospace, nuclear, environmental, robotics and other engineering disciplines. My primary method for this exposure to their broader options in the engineer profession is through the Famous Engineer presentation project.

Students are given a list of over thirty famous engineers as a suggested starting point. They can propose engineers from this list but are also encouraged to propose engineers that may not be on my list. For example, a student from India once proposed a civil engineer who was famous for his projects in India. Other students have proposed famous engineers from other countries as well. I have been flexible to approve famous mathematicians, famous entrepreneurs and famous business leaders as well. I assign presentations to begin in the second week of classes. Each class begins with two ten-minute famous engineer presentations using PowerPoint (a product of Microsoft, Inc.) software so that by the middle of the term all students have made their presentations. Students select from engineers such as Gustav Eiffel, Nikola Tesla, Burt Rutan, and many others from the past as well as current famous engineers. Through these presentations, the students become more acquainted with a wide range of engineering disciplines and thereby enable students to select or to confirm the pursuit of a particular discipline. The experience also builds self-confidence as they picture themselves making a technical presentation to an engineering board.

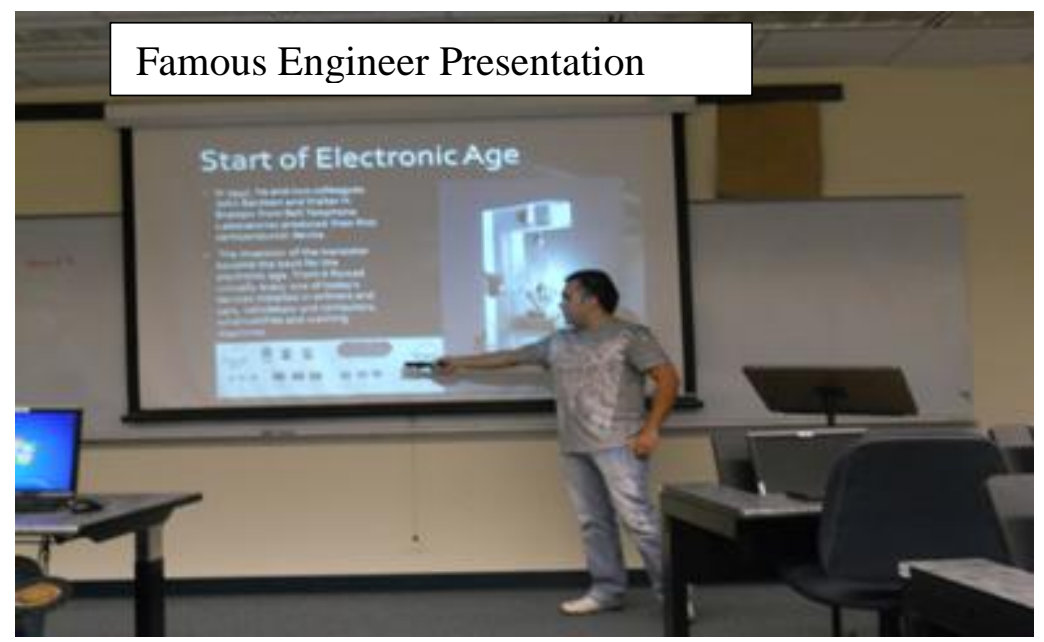

\section{Gustav Eiffel}

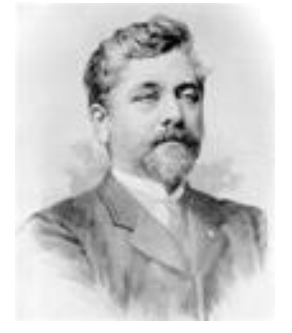

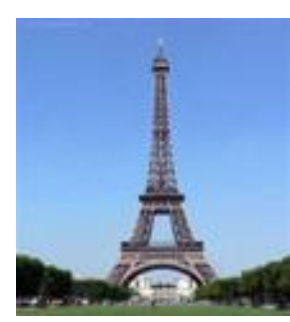

Burt Rutan
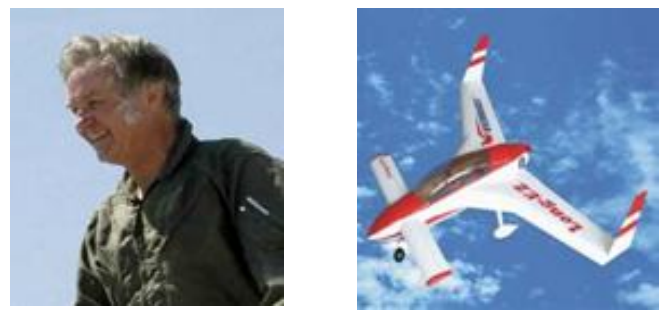
Using the Spreadsheet as an Analytical Tool

The primary tool for most engineers in industry is a desktop computer or laptop computer. The scientific calculators have become desk hermits. In the near future, the electronic tablet or smart phone will be every engineer's analytical companion. Engineering courses need to apply these ubiquitous tools to problem solving. The electronic spreadsheet, and Excel (Excel is a product of Microsoft, Inc, ) in particular, is universally used for compiling and processing extensive tabular data, creating bar charts and line charts and for importing interim results from MATLAB and other sophisticated analytical software. Freshman and sophomore engineering students want an insight to what engineers actually do on the job. They want to be inspired and challenged to adapt the tools and software that engineers actually use for problem solving and presentation of results.

When I first started teaching the Fundamentals course at PBSC, I selectively adapted the spreadsheet to solving textbook problems. However, over time, I began to adapt problems from various publications. I also formatted the problems for spreadsheet solution. Now all of my Fundamentals course assignments have been formatted for spreadsheet solution. A typical formatted assignment is illustrated in Figure 1A. In this example assignment, the area of a pond surface is to be calculated using numerical integration. The formatted table includes the offsets for each station and headings to prompt the student to calculate the interval values for Simpson's Rule and for the Trapezoidal Rule. The student is guided by instruction to apply the appropriate interval multipliers for each rule and then proceed to complete the calculation of the area of the pond surface. To keep this basic example of numerical integration simple, the volume of the pond is then estimated based on an average depth. Figure 1B illustrates the way students would complete the solution of the formatted problem. Although this problem could also be solved by using a scientific calculator, the spreadsheet is particularly amenable to the display and solution of tabular data for a number-crunching problem like this one.

\section{The Blackboard Intranet Site}

The Fundamentals course is taught in a "smart classroom" with twenty-four computers, one for each student, and an instructor's computer connected to a projector. Each computer is loaded with spreadsheet, word processing and presentation software as well as with a Blackboard (class intranet) connection. In a typical lecture, all students are sent a template through the Blackboard connection. The template is an assignment such as "Project 3.1 on Static Loads" which will be a spreadsheet file that has four to ten related problems defined. Each student must solve all problems of Project 3.1 using spreadsheet functions. Within three days of receiving the assignment, the solutions are posted in "pdf format" on Blackboard so that students can compare and correct their solutions. On major tests (there are four) and on the final exam, template files are sent to the students who then solve the problems using spreadsheet functions. At the end of 
Figure 1A: Volume of a Pond Using Numerical Integration Template

In your first project assignment as a civil engineer, you must estimate how many truckloads of dirt will be required to fill a deep pond that is in the middle of a planned road path. Your survey has given you the following surface dimensions of the pond. You have estimated from several depth readings that the average depth of the pond is ten feet ( $10 \mathrm{ft}$ ). By using numerical integration, you can calculate the area of the pond. With the average depth, you can then calculate the volume of the water in the pond that needs to be replaced with fill dirt.

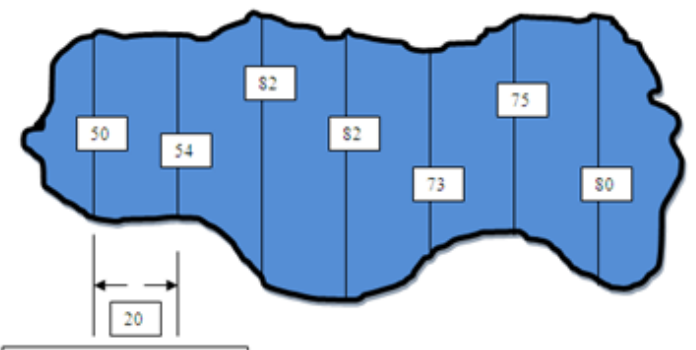

20 feet between all stations
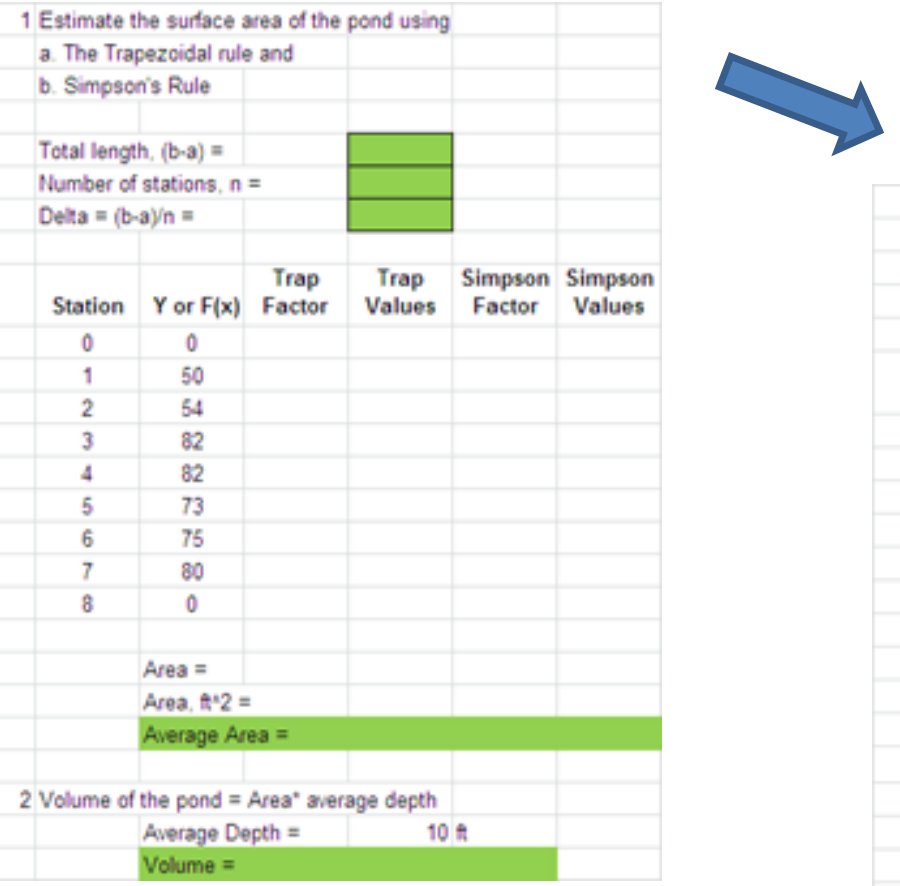

Figure 1B: Pond Area Solution

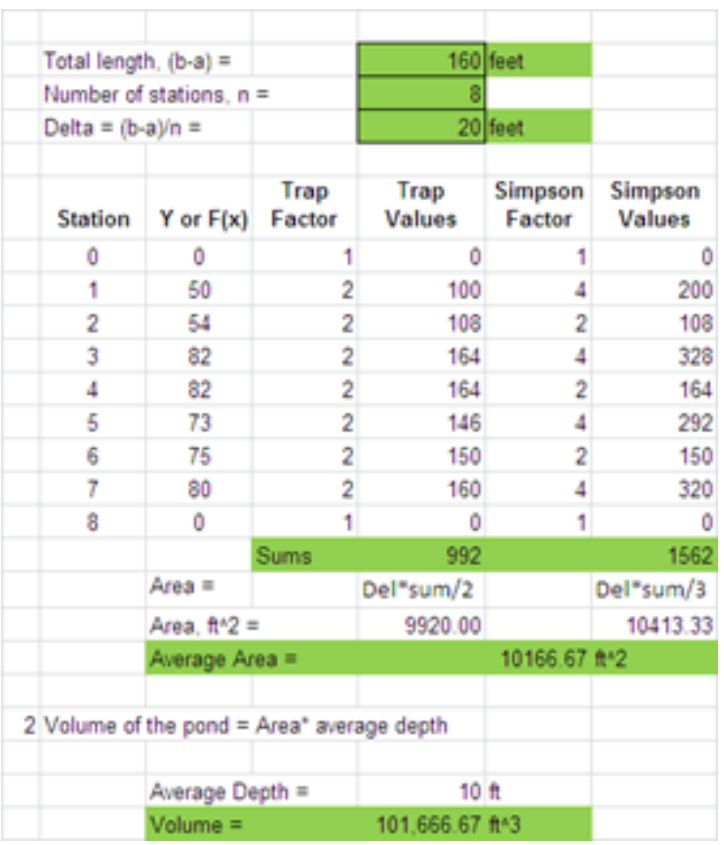


the class the test files are sent to the instructor through the attachment feature of the "Assignments" link in Blackboard. After all of the completed test files are graded, they are returned to each respective student through Blackboard. All file exchanges and all class instructional materials are processed through Blackboard. The course is virtually paperless.

Course Topical Groups

In addition to the Famous Engineer presentations, the Fundamentals course is basically composed of five topical groups:

Group 1: Office Productivity Software (using Microsoft Office)

Group 2: Charting and Statistics

Group 3: Static Loads Analysis

Group 4: Dynamics

Group 5: DC and AC Circuit Analysis

Group 1: Office Productivity Software

Group 1 is a general introduction to the use of word-processing (Microsoft Word) and the electronic spreadsheet (Microsoft Excel). In Group 1, the students perform several basic spreadsheet projects in class under the guidance of the instructor:

$>$ Project 1.1: Student Biography (1 word-processed page) where the student writes about his or her background and interest in engineering. The student also proposes a Famous Engineer for his or her presentation.

$>$ Project 1.2: Spreadsheet Exercises (four classroom exercises):

$>$ Project 1.2A: Create a "Trigonometry Table" using drawing features and math functions of Excel.

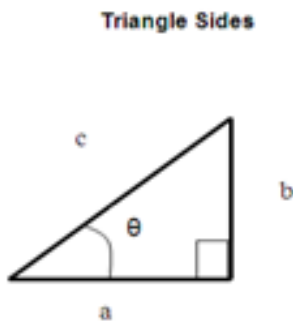

\begin{tabular}{|c|c|c|c|c|}
\hline \multicolumn{4}{|c|}{ Calculate Cosine \& Sine from Degrees } & \multirow[b]{2}{*}{ b } \\
\hline & & c & a & \\
\hline Degr, $\theta$ & Rdns, $\theta$ & Hyp & $\operatorname{Cos} \theta$ & $\sin \theta$ \\
\hline 10 & 0.1745 & 5 & 4.9240 & 0.8682 \\
\hline 20 & 0.3491 & 5 & 4.6985 & 1.7101 \\
\hline 30 & 0.5236 & 5 & 4.3301 & 2.5000 \\
\hline 40 & 0.6981 & 5 & 38302 & 32139 \\
\hline 45 & 0.7854 & 5 & 35355 & 3.5355 \\
\hline 50 & 0.8727 & 5 & 32139 & 3.8302 \\
\hline 60 & 1.0472 & 5 & 25000 & 4.3301 \\
\hline 70 & 1.2217 & 5 & 1.7101 & 4.6985 \\
\hline 80 & 1.3963 & 5 & 0.8682 & 4.9240 \\
\hline 90 & 1.5708 & 5 & 0.0000 & 5.0000 \\
\hline
\end{tabular}

Project 1.2B: Create a "Mortgage Table: using the finance functions, cell referencing, cell labeling, and row hiding features of Excel.

\begin{tabular}{|r|r|r|r|r|}
\hline Principle & Intr RUyr & $\begin{array}{r}\text { Years } \\
30.00\end{array}$ & \\
\hline 250.000 & $6.500 \%$ & $\begin{array}{r}3 \\
\text { Months }\end{array}$ & PU/Mo & \\
\hline & 0.005417 & 360.00 & 1.580 .17 & \\
\hline & & & & \\
\hline Month & Principle & Interest & Prin Paymnt & Cum Interest \\
\hline 1 & 250.000 .00 & 1.354 .17 & 226.00 & 1.354 .17 \\
\hline 12 & 247.445 .53 & 1.340 .33 & 239.84 & 16.167 .73 \\
\hline 24 & 244.480 .13 & 1.324 .27 & 255.90 & 32.148 .31 \\
\hline 348 & 19.783 .96 & 107.16 & 1.473 .01 & 318.210 .14 \\
\hline 360 & 1.571 .66 & 8.51 & 1.571 .66 & 318.861 .22 \\
\hline
\end{tabular}


Project 1.2C: Apply the data sorting features of Excel for one and two level sorting examples.

\begin{tabular}{|c|c|c|c|c|}
\hline \multicolumn{3}{|c|}{ Ex 1.2 C: Database Sorting } & \multicolumn{2}{|c|}{2003 Engr Salary De } \\
\hline \multicolumn{5}{|c|}{ Downloaded Salary Data } \\
\hline Title & Type & Avg Min Sal & Avg Max Sal & Avg Bonus \\
\hline Eng. Lab Assistant & ÉE & 517.163 & $\$ 27,109$ & $\$ 543$ \\
\hline Electronics Tech & $\mathrm{EE}$ & $\$ 21.074$ & $\$ 32,717$ & $\$ 675$ \\
\hline Hardware Engineer & $\mathrm{ME}$ & $\$ 32.180$ & $\$ 51.847$ & $\$ 1.493$ \\
\hline Mechanical Engineer & ME & $\$ 41.359$ & $\$ 66.032$ & $\$ 1,643$ \\
\hline Civil Engineer & $\mathrm{CE}$ & $\$ 42.047$ & $\$ 67.174$ & $\$ 1,321$ \\
\hline Electrical Engineer & EE & $\$ 42.776$ & $\$ 67.205$ & $\$ 1.888$ \\
\hline Chemical Engineer & ChE & $\$ 49.457$ & $\$ 79.796$ & $\$ 1.805$ \\
\hline Electrical Eng Sup & $\mathrm{EE}$ & $\$ 57.613$ & $\$ 92.486$ & $\$ 3.890$ \\
\hline Mech Eng Supervisor & $M E$ & 557.897 & $\$ 83,597$ & $\$ 2,180$ \\
\hline Civil Engineering Sup & $\mathrm{CE}$ & $\$ 59.860$ & $\$ 85.358$ & $\$ 2.547$ \\
\hline Chem Eng Supvr & ChE & $\$ 76.738$ & $\$ 96.883$ & $\$ 2.965$ \\
\hline VP. Engineering & ChE & $\$ 93.296$ & $\$ 223.634$ & $\$ 14.578$ \\
\hline
\end{tabular}

Project 1.2D: Determine the "Surface Area of a Pond Using Numerical Integration". Refer to Figure 1A and Figure 1B.

These projects build the foundation for confidence in the use of the electronic spreadsheet as a tool for solving engineering problems. Students are then assigned several other projects where they must apply the demonstrated spreadsheet skills independently.

\section{Group 2: Charting and Statistics}

In Group 2, students learn how to use the "Excel Chart Wizard" effectively for creating various types of charts including column charts, line charts and scatter charts. Excel Chart Wizard uses artificial intelligence to assume some parameters for the chart that are often extraneous. Students learn how to edit the data entry process (through the Data Select feature) to produce the intended chart results. Students also learn how to produce semi-log charts with the charting features of Excel. As part of Group 2, students learn how the spreadsheet can be very effective in producing histogram column charts. Additionally, students are introduced to the "Trendline" feature of Excel in formulating both linear and non-linear equations from empirical data. Lastly, the normal distribution functions of Excel are used to identify the probability ranges that may apply for normally distributed data. Some of these charting projects are classroom projects guided by the instructor but students are also assigned similar projects to be completed independently. A primary deliverable in Group 2 is a hard copy report of the charts that are prepared in this group. This is the only hard copy assignment the students receive. 


\section{Column Chart}

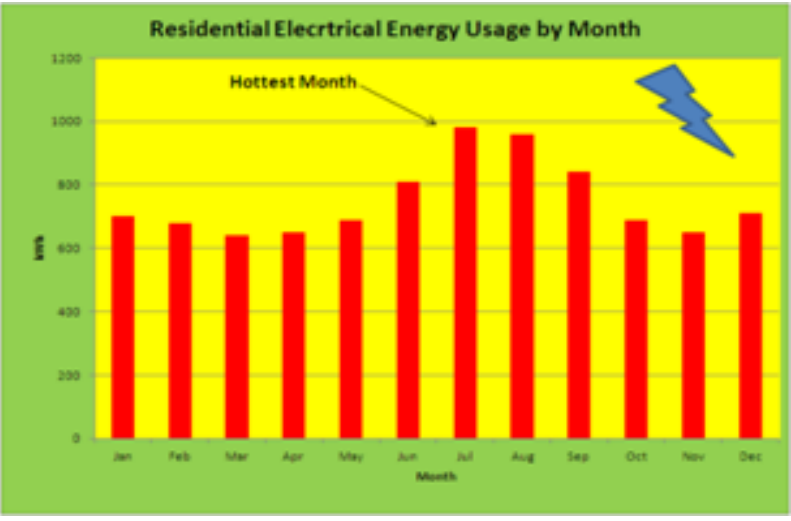

Histogram using Column and Line Charts

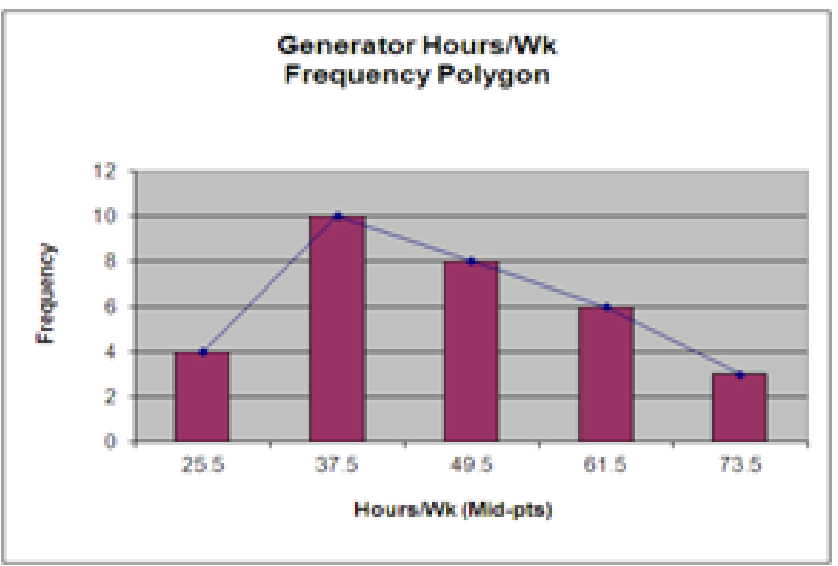

\section{Normal Distribution Diagram}

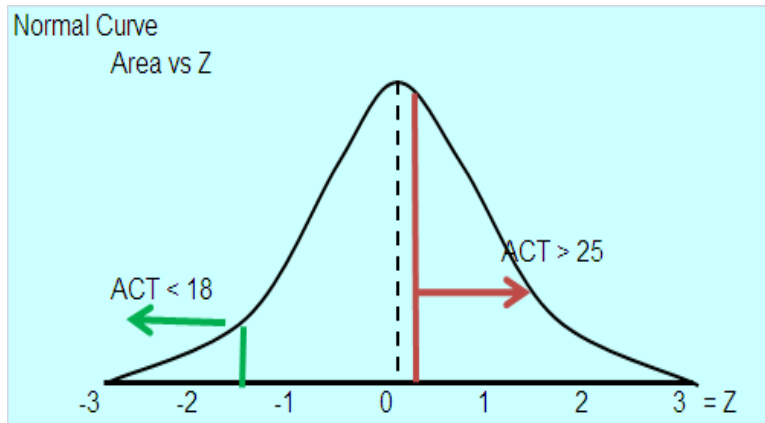

Scatter Chart with Semi-log Scale

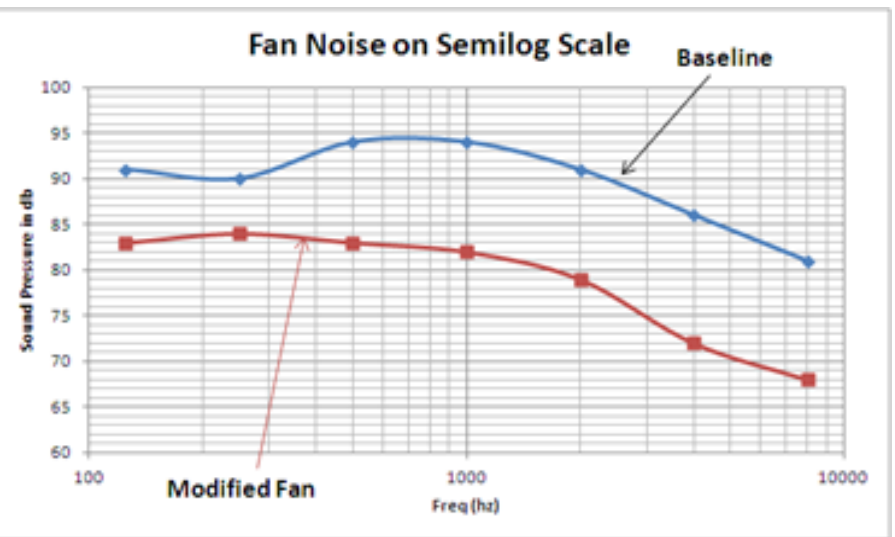

Trendline Chart

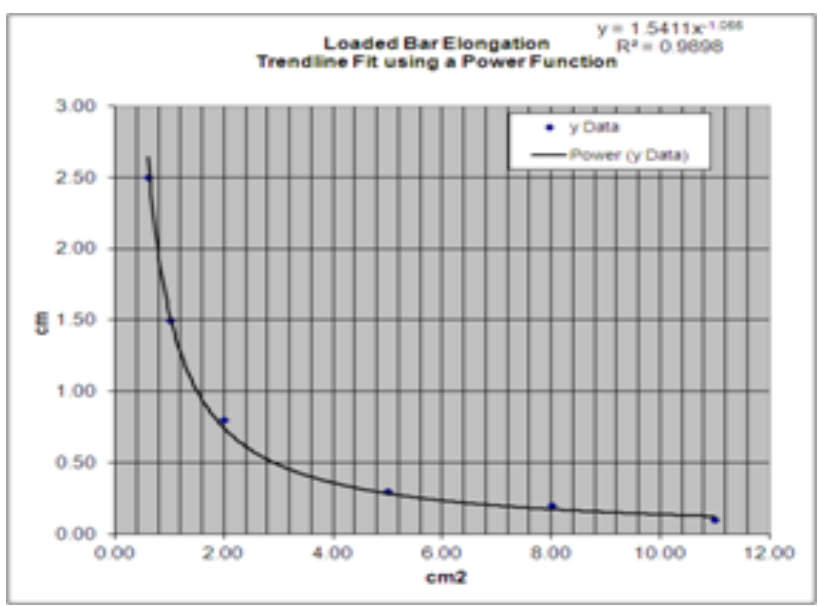


Group 3: Static Loads Analysis

Group 3 is an introduction to the analysis of static loads which are important to both civil and mechanical engineering students. In an example from Group 3 on static loads, a loaded beam is formatted in Figure $2 \mathrm{~A}$ to show the applied forces. The objective of the problem is to find the reaction forces. The template prompts the student to first find the orthogonal components of the given forces. Tables are set up to then guide the student towards the balancing of moments. The solution of the loaded beam problem is illustrated in Figure $2 \mathrm{~B}$. The student would move the appropriate moment curls into place on the loaded beam. A "moments table" prompts the student to calculate the moments and confirm that they balance (add up to zero). One of the reaction forces can then be identified. Tables for balancing the X-forces and Y-forces then prompt the student to find all of the reaction forces as required. More complex static loads problems are assigned to promote a more thorough understanding of the rules for balancing moments and forces in determining reaction forces.

Figure 2A: Loaded Beam Forces Template

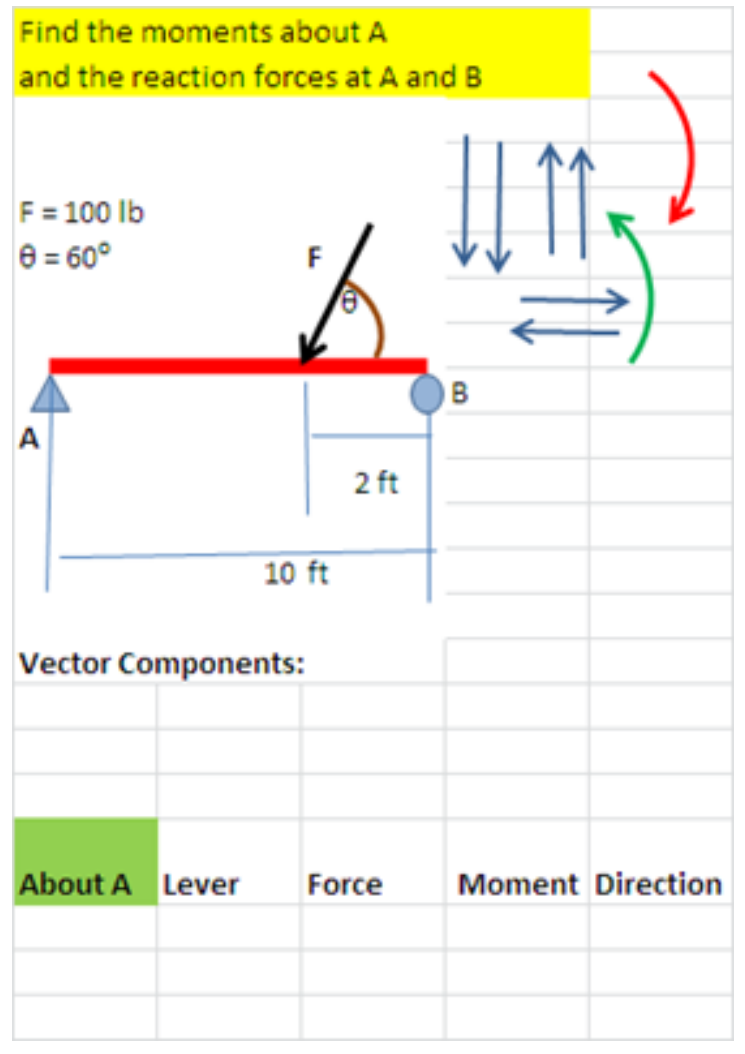

Figure 2B: Solution to the Loaded Beam Forces

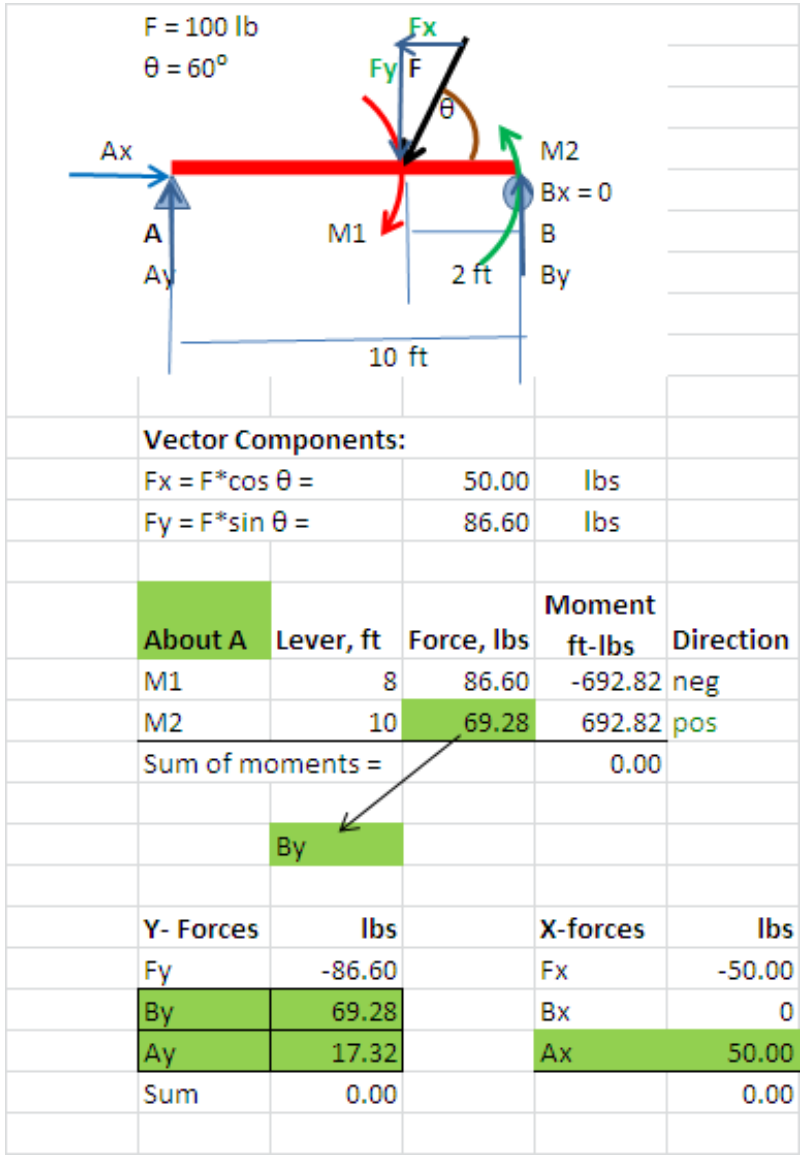


Truss forces are also analyzed in the study of static loads in Group 3. In Figure 3A, a template establishes the given forces and the geometry for a simple truss problem. The objective is to find the tensile and compressive forces along each beam. In the partial solution illustrated in Figure 3B, once the reaction forces are found, then a balance of forces must be found at each truss junction. It is a laborious process when several junctions must be analyzed but the exercises reinforce the concept of the balancing of forces for static loads problems. Using the spreadsheet approach promotes careful organization of the problem and exemplifies a disciplined approach to solving complex problems in general.

Figure 3A: Truss Forces Template

For the simple truss below, find the forces along $\mathrm{AB}$ and $\mathrm{AC}$. Identify which member is in tension and which one is in compression.

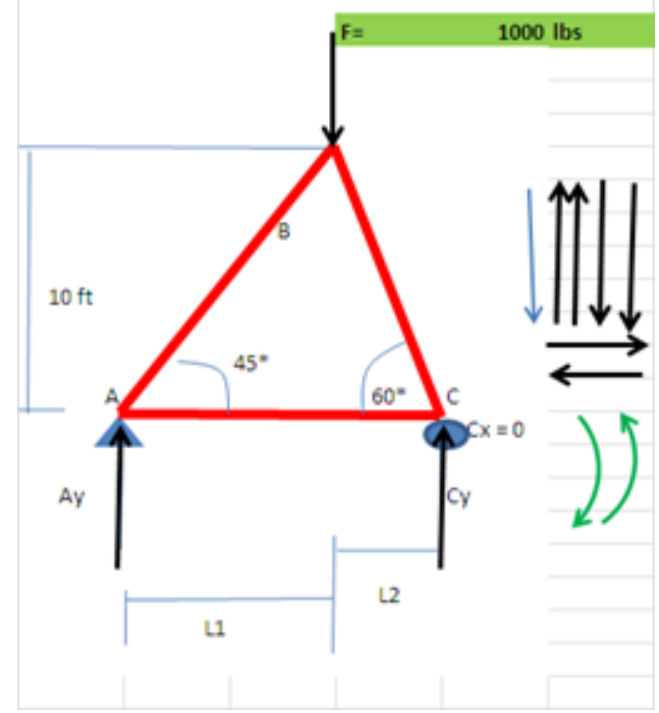

Figure 3B: Truss Forces Solution

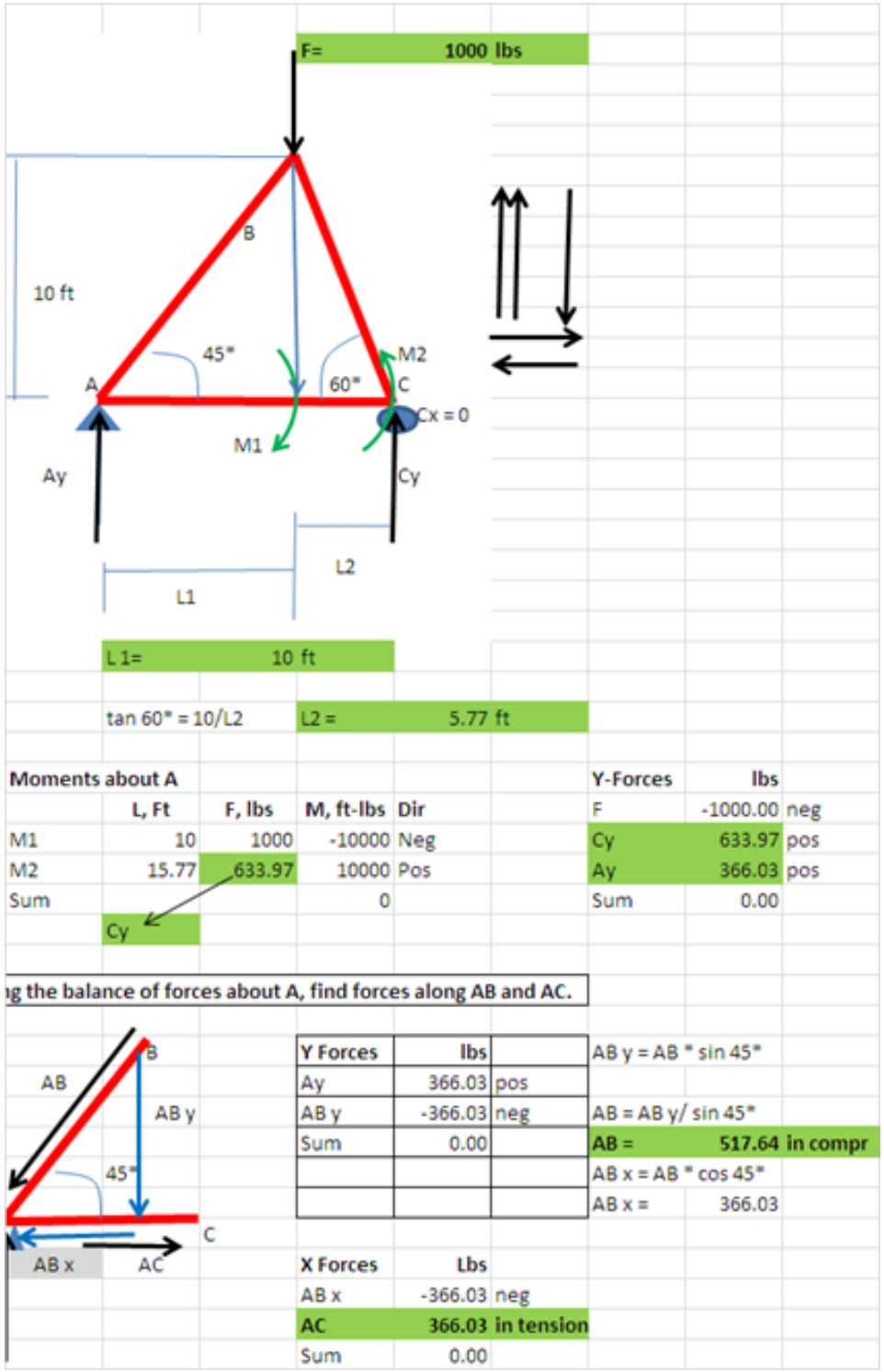


Group 4: Dynamics

In Group 4 on dynamics, the subtopics include kinematics, kinetics and Newton's second law regarding moving bodies. Figure $4 \mathrm{~A}$ is a template for a typical problem that requires an understanding of rectilinear motion and circular motion. As shown in the solutions of Figure 4B, the student is prompted to demonstrate an understanding of linear velocity and acceleration as well as angular velocity and acceleration. The problem also requires calculation of tangential acceleration and radial acceleration. Although these kinds of calculations can also be easily solved with a calculator, the discipline of organizing multiple solutions for the given multi-stage problem offers the student experience with a rigorous approach.

The dynamics group, also includes exploration of energy, work and power. Figure 5 illustrates a typical solution for a work and energy problem. The original template was designed to prompt the student into the solution process.

\section{Group 5: DC and AC Circuit Analysis}

In the last group, Group 5, basic electric circuit analysis is explored for both directcurrent and alternating current circuits. In the template of Figure 6A, the student is expected find the voltage drops across each resistor and a current through each resistor using Ohm's Law and Kirchoff's laws. The solution shown on Figure 6B illustrates that students must identify where the currents will be common and where the voltage drops will be common.

For alternating currents, the students must calculate the phase angles between current and voltage through capacitors and inductors. They can then calculate the power demand of the circuit. Figure 7A is a template for an RLC series circuit. Figure 7B illustrates the solution for the given RLC series circuit. In this example, the student must first calculate capacitive reactance and inductive reactance. Resistance and reactance components are separated between real and imaginary axes allowing the calculation of both impedance and phase angle. The student must then sketch the voltage-current phasors as well as the resistance-reactance vectors. Using the circuit impedance and applied voltage, the current going through the effective series of resistances and reactances can be calculated. Once the current is known, voltage drops across each component can be calculated. The Pythagorean sum of the real and imaginary voltage drops should result in a total effective voltage drop that should equal the applied voltage gain. Finally, the power required by the circuit can be calculated from the applied voltage and total circuit current for the derived phase angle. Parallel AC circuits can be analyzed in a similar way with this logical tabular approach. 
Figure 4A: Kinematics Problem Template

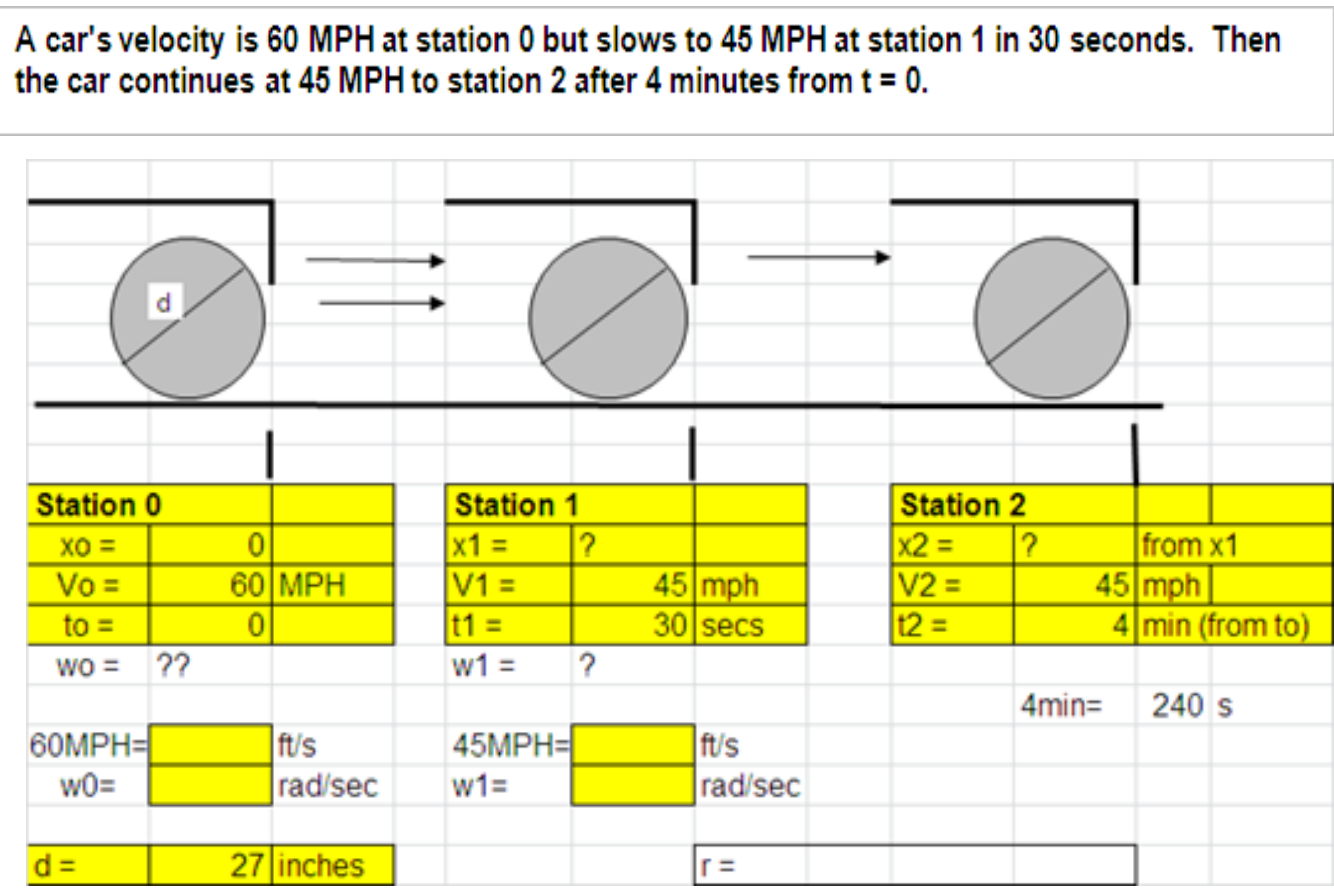

Figure 4B: Kinematics Problem Solution

\begin{tabular}{|c|c|c|c|c|c|c|c|c|c|c|c|}
\hline \multirow{2}{*}{$\begin{array}{c}60 \mathrm{MPH}= \\
\mathrm{wO}=\end{array}$} & 88 & \multicolumn{2}{|l|}{ ft/s } & \multirow{2}{*}{$\begin{array}{l}45 \mathrm{MPH}= \\
\mathrm{w} 1=\end{array}$} & \multicolumn{2}{|c|}{$66 \mathrm{ft} / \mathrm{s}$} & & & & & \\
\hline & 78.222 & \multicolumn{2}{|c|}{$\mathrm{rad} / \mathrm{sec}$} & & 58.67 & \multicolumn{2}{|c|}{$\mathrm{rad} / \mathrm{sec}$} & & & & \\
\hline \multirow{23}{*}{$\mathrm{d}=$} & 27 & inches & $=$ & 225 & $\mathrm{ft}$ & $r=$ & & 1.125 & $\mathrm{ft}$ & & \\
\hline & & & & & & & & & & & \\
\hline & \multicolumn{3}{|c|}{ At station 1 find: } & \multirow{2}{*}{\multicolumn{8}{|c|}{$\begin{array}{l}\text { Show equations and calculations below and } \\
\text { then show the answers in the highlighted boxes. }\end{array}$}} \\
\hline & & & & & & & & & & & \\
\hline & & & & & & & & & Units & & \\
\hline & $\mathrm{a}$ & \multicolumn{6}{|c|}{ distance traveled to $\times 1$ in $\mathrm{ft}, \mathrm{x} 1=$} & 2310 & $\mathrm{ft}$ & & \\
\hline & $\mathrm{b}$ & \multicolumn{5}{|c|}{ angular velocity of w1 in rpm and rdns } & $w 1=$ & 58.67 & $\mathrm{rdns} / \mathrm{s}=$ & 560.2 & RPM \\
\hline & C & \multicolumn{5}{|c|}{ linear acceleration, a in $\mathrm{ft} / \mathrm{s}^{\wedge} 2$} & $a=$ & -0.73 & $\mathrm{ft} / \mathrm{s}^{\wedge} 2$ & & \\
\hline & $\mathrm{d}$ & \multicolumn{5}{|c|}{ angular acceleration, @ in rdns $/ \mathrm{s}^{\wedge} 2$} & $@=$ & -0.65 & $\mathrm{rdns} / \mathrm{s}^{\wedge} 2$ & & \\
\hline & e & \multicolumn{5}{|c|}{ tangential acceleration, $\mathrm{a}_{\mathrm{T}}$} & $\mathrm{a}_{\mathrm{T}}=$ & -0.73 & $\mathrm{ft} / \sec ^{\wedge} 2$ & & \\
\hline & $f$ & \multicolumn{5}{|c|}{ radial acceleration, $\mathrm{a}_{\mathrm{R}}$} & $a_{R}=$ & 3872 & $\mathrm{ft} / \sec ^{\wedge} 2$ & & \\
\hline & g & \multicolumn{5}{|c|}{ the total effective acceleration vector, } & $a_{E}=$ & 3872 & $\mathrm{ft} / \sec ^{\wedge} 2$ & & \\
\hline & i & \multicolumn{7}{|c|}{ The total distance traveled in $\mathrm{ft}$ and in miles, $\mathrm{x}_{\mathrm{T}}$. } & & & \\
\hline & & & & & & & & & & & \\
\hline & & $\mathrm{t} 2$ & 4 & $\min =$ & 240 & secs & & & & & \\
\hline & & $\mathrm{t} 1=$ & & & 30 & \multirow{2}{*}{\multicolumn{3}{|c|}{ secs (given) }} & & & \\
\hline & & $\mathrm{t}$ net $=$ & & & 210 & secs & & & & & \\
\hline & & & & & & & & & & & \\
\hline & & $\times 2=$ & 66 & $\mathrm{ft} / \mathrm{s}^{*}$ & 210 & secs $=$ & & $\times 2=$ & 13860 & $\mathrm{ft}$ & \\
\hline & & \multicolumn{3}{|c|}{ from part a: } & & & & $\mathrm{x} 1=$ & 2310 & $\mathrm{ft}$ & \\
\hline & $\mathrm{i}$ & \multicolumn{6}{|c|}{$\mathrm{xt}=\mathrm{x} 1+\mathrm{x} 2=$} & $\mathrm{xt}=$ & 16170 & $\mathrm{ft}$ & \\
\hline & $\mathrm{i}$ & \multicolumn{6}{|c|}{$\mathrm{xt}$ in miles $=$} & $\mathrm{xt}=$ & 3.06 & Miles & \\
\hline & j & \multicolumn{6}{|c|}{ The total angular displacement $=$} & $\mathrm{xt} / \mathrm{r}=$ & 14373 & rdns & \\
\hline
\end{tabular}


Figure 5: Energy, Work and Power Solution (template over-written)

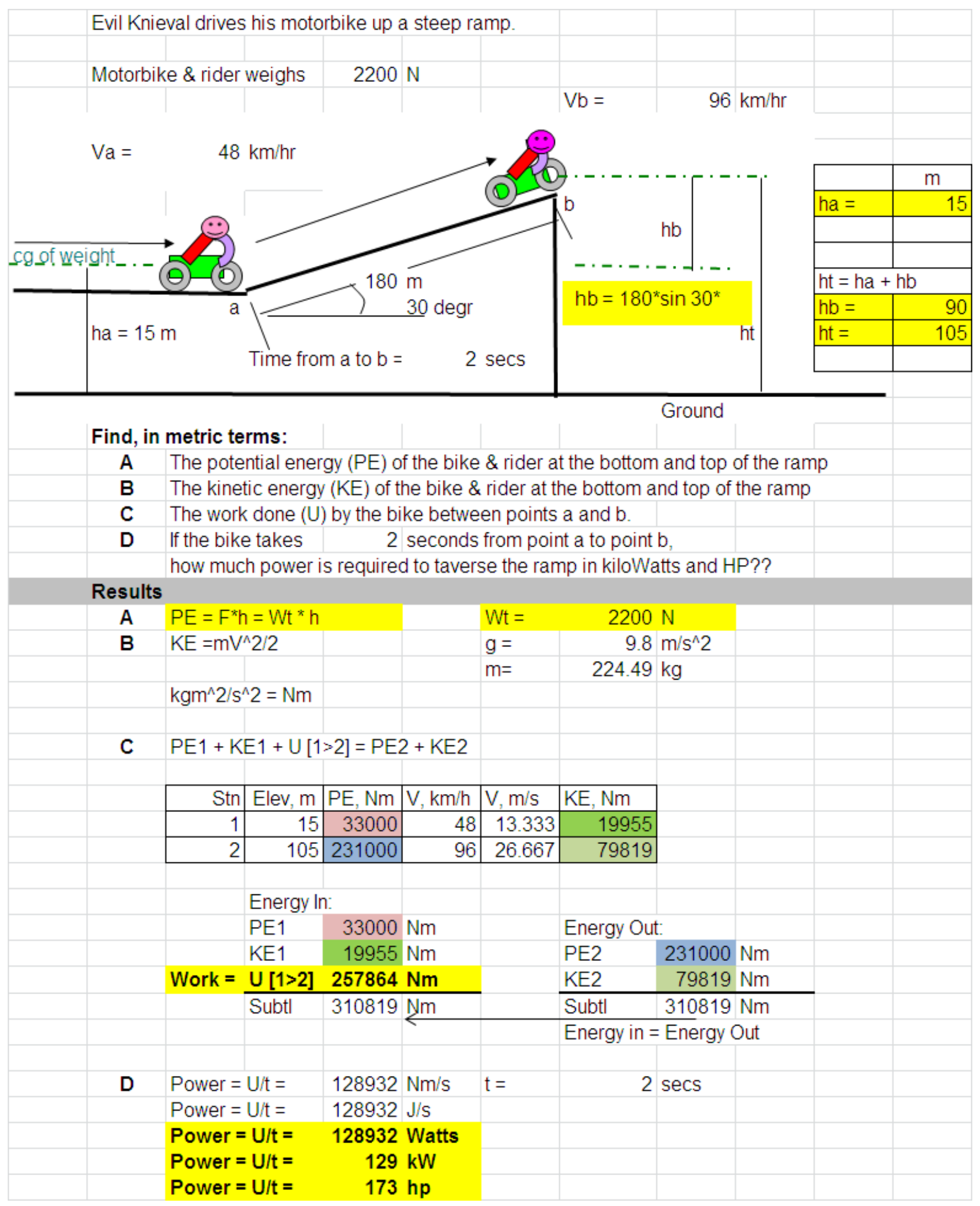


Figure 6A: DC Electric Circuit Template

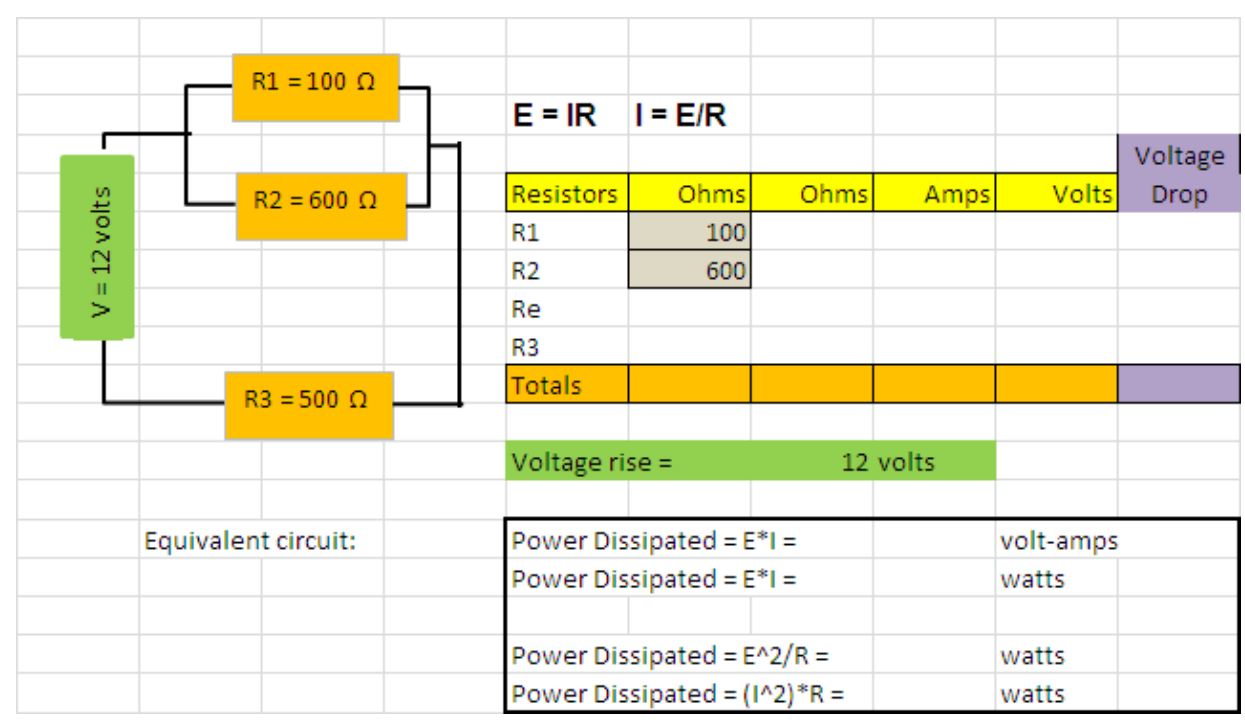

Figure 6B: DC Electric Circuit Solution

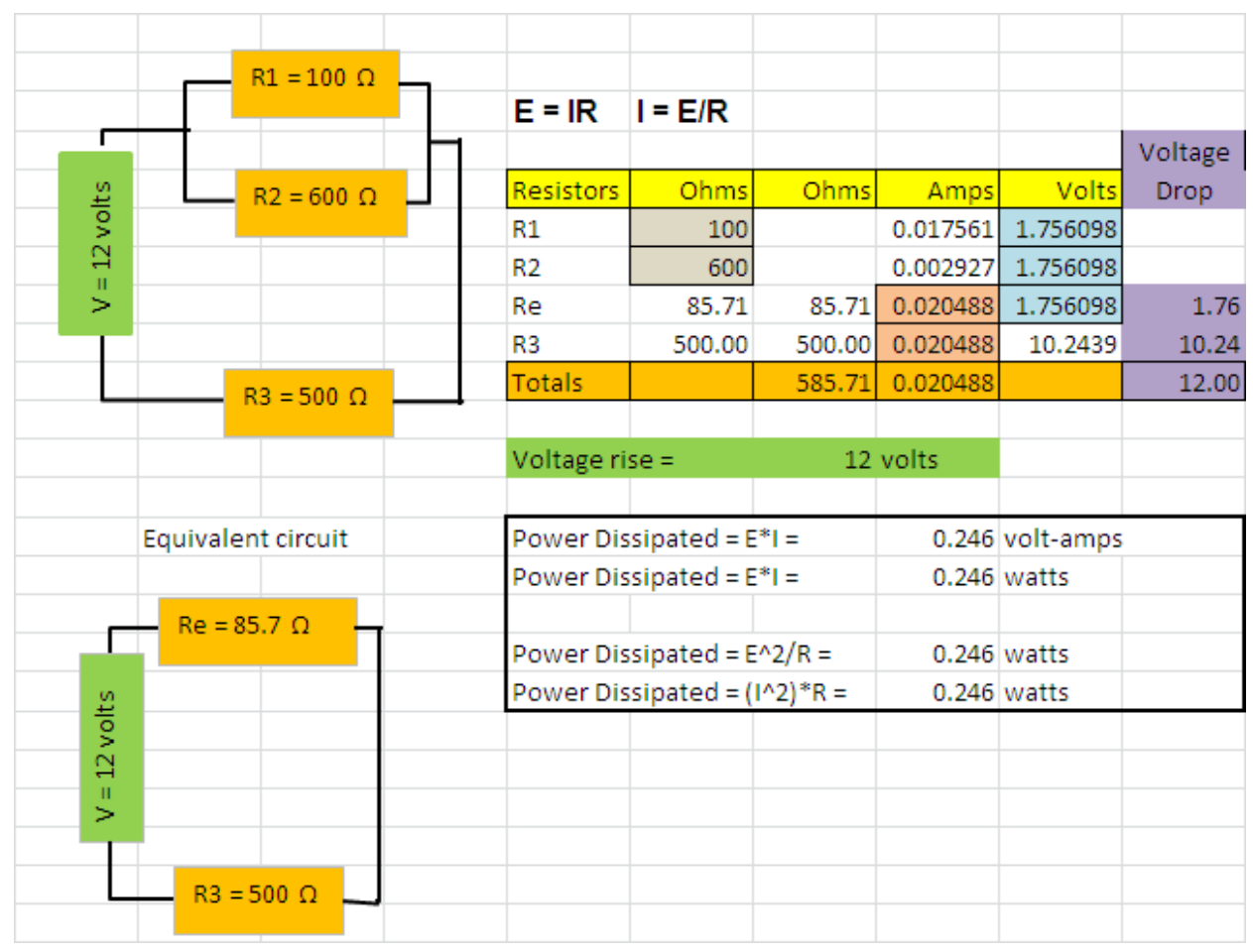


Figure 7A: AC Electric Circuit Template

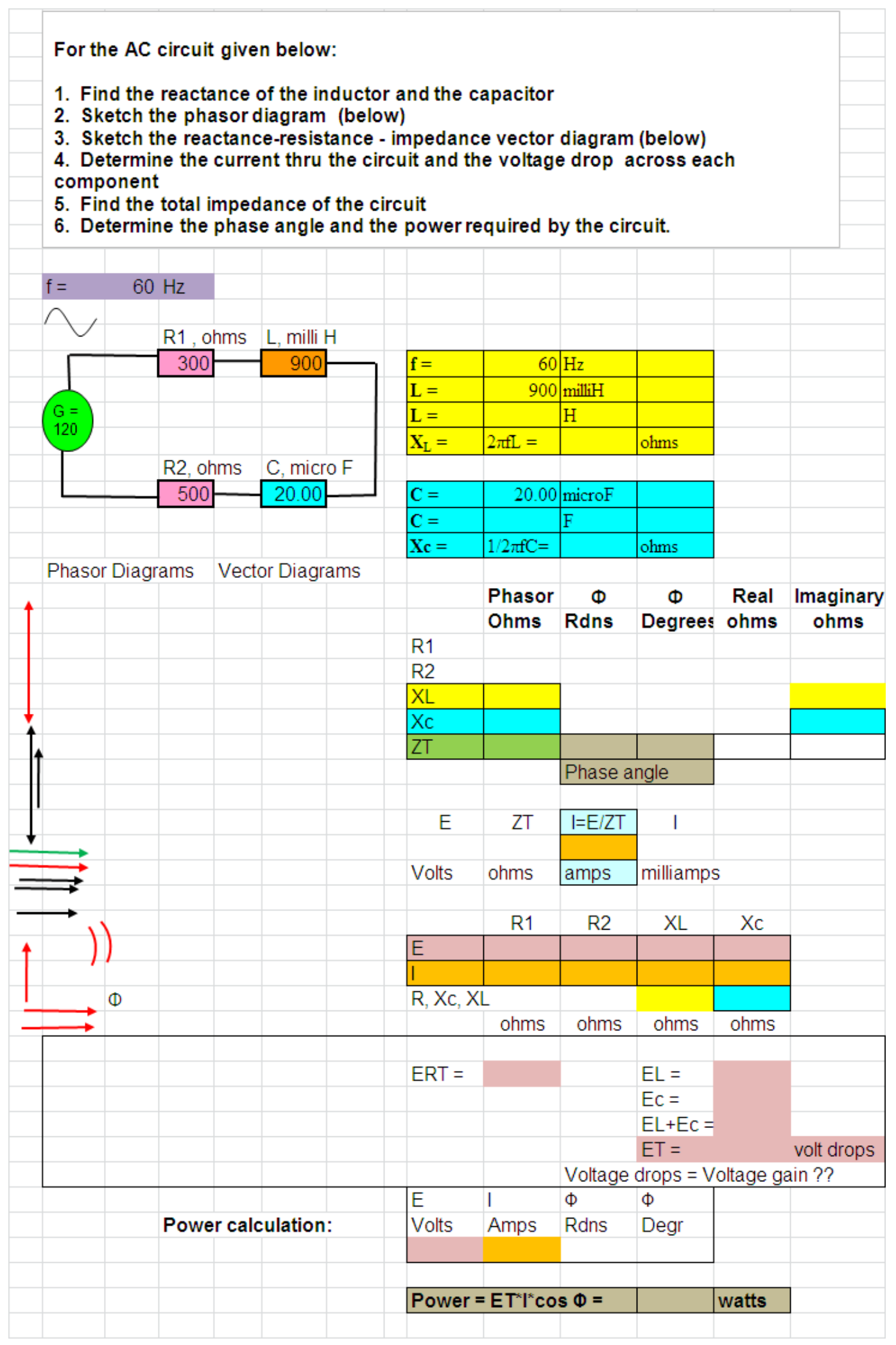


Figure 7B: AC Electric Circuit Solution

For the AC circuit given below:

1. Find the reactance of the inductor and the capacitor

2. Sketch the phasor diagram (below)

3. Sketch the reactance-resistance - impedance vector diagram (below)

4. Determine the current thru the circuit and the voltage drop across each component

5. Find the total impedance of the circuit

6. Determine the phase angle and the power required by the circuit.

\section{$\mathrm{f}=\quad 60 \mathrm{~Hz}$}

R1, ohms L, milli $\mathrm{H}$

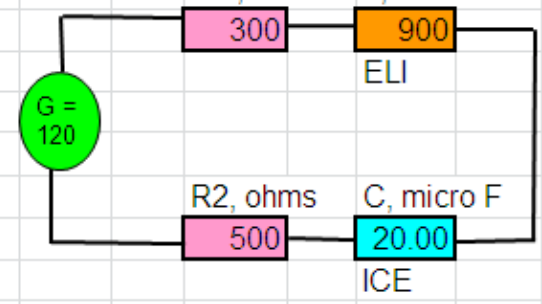

\begin{tabular}{|l|r|l|l|}
\hline $\mathbf{f}=$ & 60 & $\mathrm{~Hz}$ & \\
\hline $\mathbf{L}=$ & 900 & milliH & \\
\hline $\mathbf{L}=$ & 0.9 & $\mathrm{H}$ & \\
\hline $\mathbf{X}_{\mathrm{L}}=$ & $2 \pi \mathrm{fL}=$ & $\mathbf{3 3 9 . 2 9}$ & ohms \\
\hline
\end{tabular}

\begin{tabular}{|l|r|l|l|}
\hline $\mathbf{C}=$ & 20.00 & microF & \\
\hline $\mathbf{C}=$ & 0.00002 & $\mathrm{~F}$ & \\
\hline $\mathbf{X c}=$ & $1 / 2 \pi \mathrm{fC}=$ & $\mathbf{1 3 2 . 6 3}$ & ohms \\
\hline
\end{tabular}

Phasor Diagrams Vector Diagrams

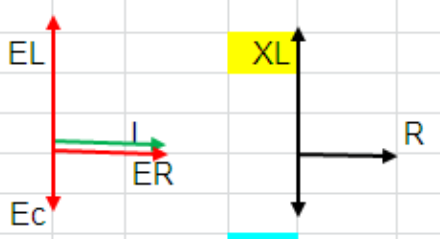

$\mathrm{Xc}$

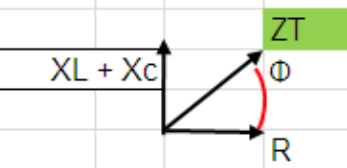

\begin{tabular}{|c|c|c|c|c|c|}
\hline & Phasor & $\Phi$ & $\Phi$ & Real & Imaginary \\
\hline & Ohms & Rdns & Degrees & ohms & ohms \\
\hline R1 & 300 & & & 300 & \\
\hline R2 & 500 & & & 500 & \\
\hline $\mathrm{XL}$ & 339.29 & & & & 339.29 \\
\hline Xc & 132.63 & & & & -132.63 \\
\hline ZT & 826.26 & 0.2528 & 14.48 & 800 & 207 \\
\hline
\end{tabular}

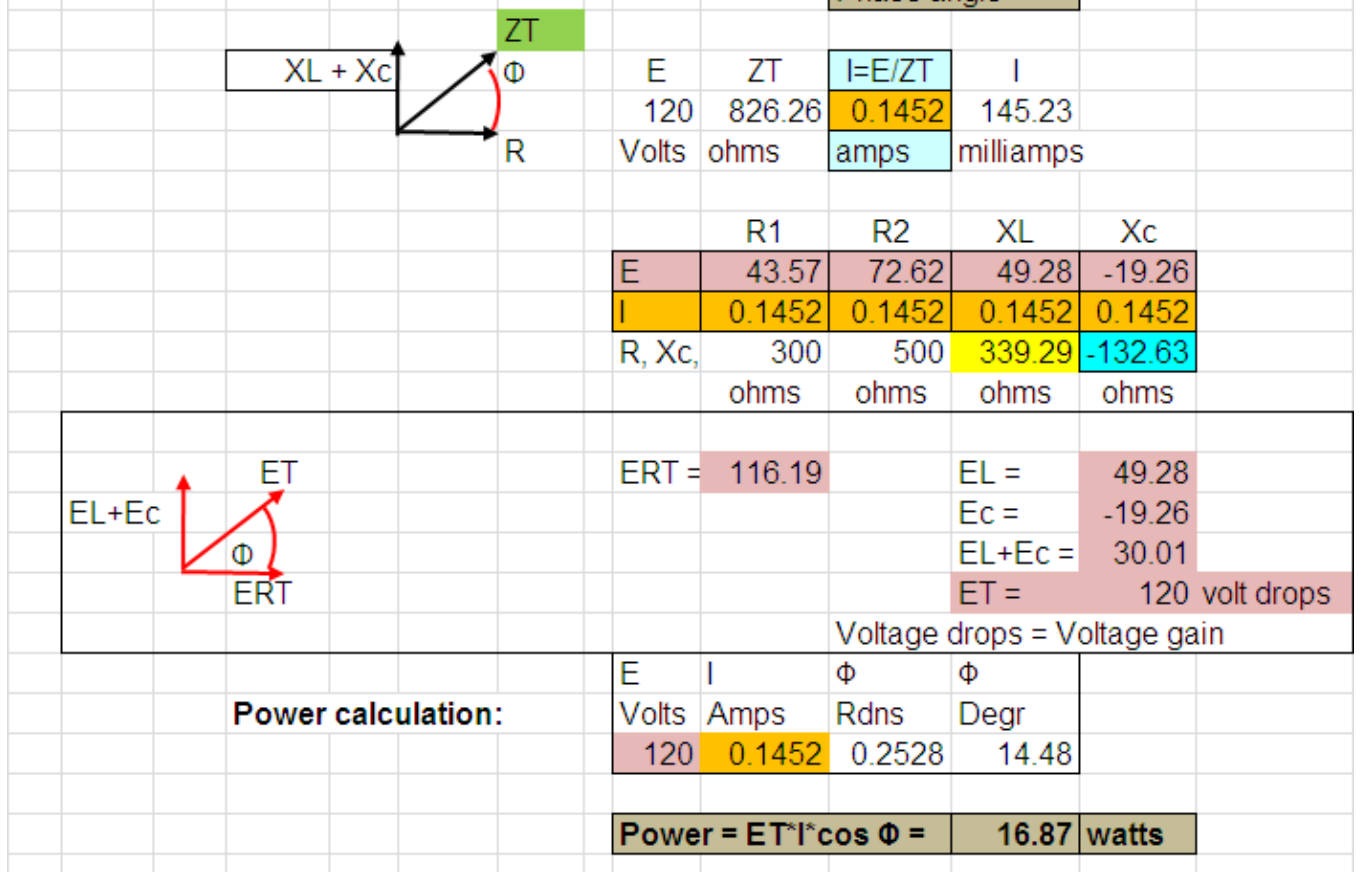




\section{Assignments and Tests}

My course is structured to hold four major tests and a final exam. Class time is 110 minutes (one hour and $50 \mathrm{~min}$.) twice per week. Since most of the test problems tend to have multiple parts, the major tests and the final exam must be limited to four problems. The tests are relatively easy to grade. Once the electronic files for the test have been sent as an attachment through the assignments link in Blackboard, those files can be highlighted for corrections and marked for points as shown in Figure 8. Then a total score which can be compiled on a score table on the same file. The graded file is then re-saved to include the markup. Once all of the test files are graded, they can then be returned to the students through the attachment feature of the Assignments link in Blackboard. As those graded files are returned, the grades are also sent to the Gradebook feature of Blackboard. As a result, the students receive their marked-up spreadsheet solutions with my corrections and an update to their current course grade. Consequently, students are always aware of their current grades and their overall grade performance throughout the term.

\section{Classroom Logistics}

Many colleges are reluctant to invest in smart classrooms with hundreds of computers that need to be maintained and software that must be continuously updated. In particular, commercial software can be very expensive even for student packages. However, the computers and software are becoming cheaper than books. Most students, and particularly engineering students, already own a laptop computer and bring it to campus daily. Computers are used for taking notes and exchanging files for various courses, so they are not exclusively used for engineering courses. Given the widespread use of a laptop computer by students why not require engineering students to buy the hardware and software as a requirement for engineering classes. The hardware and software standards for personal laptop computers can be made available through the college website. The purchase of the required hardware and software would be no different than the purchase of textbooks. The cost of a computer loaded with all of the commonly used software and electronic reference materials can easily be justified over the wide usage for other college courses. Most engineering students have made the investment anyway. With this strategy, the college could eliminate the need for computerized classrooms. A very much more practical and economical alternative would be to convert classrooms to offer electrical outlets at each desk or station so that students can plug-in their laptops for non-interrupted power. Most college campuses now offer Wi-Fi campus-wide, so access to the Internet and to the individual course intranets is possible without cable connections.

All of the office applications software for word-processing, spreadsheet and presentation operations are using universal file formats and are now available for free. OpenOffice application software offers most of the features of commonly used office software. Some of my students have used OpenOffice spreadsheet software instead of Excel with very little noticeable difference. The operational steps are very similar between software types, so switching between 
Figure 8: Graded Test Problem (mark-up in pink highlight)

\section{Problem \# 1: Truss Loads at a Junction}

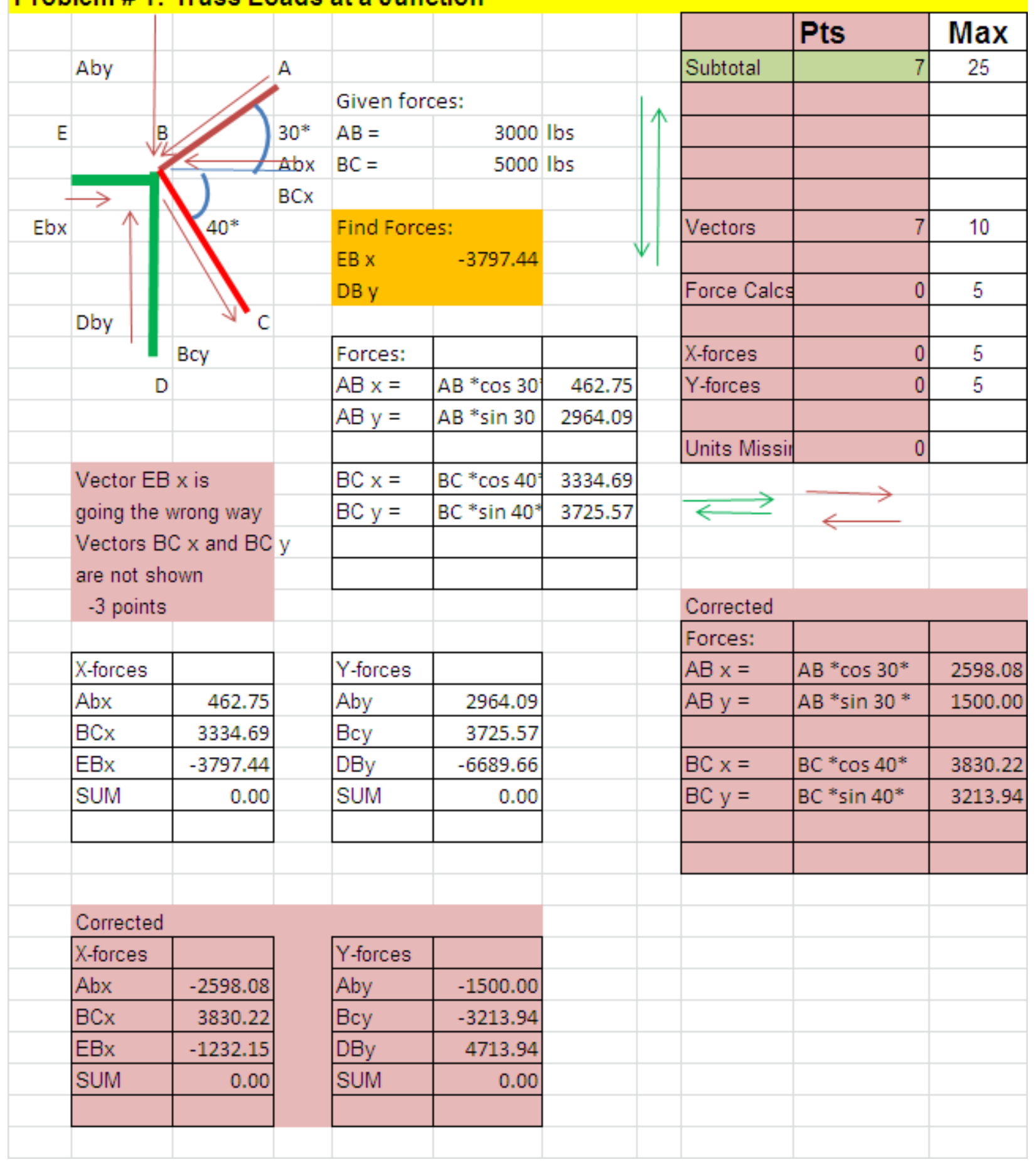


OpenOffice to some other office applications package should be easy. Eventually, with "cloud computing", OpenOffice may become more widely used.

In essence, the cost of offering computers and software for college courses need not be a concern for college computer services departments. It will not be particularly burdensome to the students to maintain their own computers and software. Engineering colleges must offer instruction using the tools and techniques that will be expected by the technical industry of the next generation. The scientific calculator sits the same drawer with the slide rule. The next tool will be the electronic tablet. Some private grade schools now require their students to purchase and Apple iPad for their classes. Their electronic tablets are loaded with all the textbook materials they may need. Eventually, the textbook could become a museum piece. Anyone who reminisces for the "traditional" way courses were taught is going to be left in the dust of the "connected student" of the future. Tradition is the artifact of the obsolete.

Conclusions

As previously indicated, the primary objective of the Fundamentals course is to prepare students for success in their pursuit of an engineering education and an engineering career. In support of this primary objective, the Fundamentals course at PBSC is designed to produce the following learning outcomes:

1. Students learn how to use the electronic spreadsheet effectively for:

$>$ Creating complicated analytical tables

$>$ Creating various types of charts

$>$ Database operations

$>$ Applying drawings and figures to word files and spreadsheet files

$>$ Importing figures and pictures to files

2. Students learn to use Blackboard as an "Intranet" communication tool

$>$ for secure e-mail communication within the intranet

$>$ for receiving and sending announcements

$>$ for keeping up with individual grade performance

$>$ for receiving and submitting assignments

$>$ for downloading tests and submitting tests on-line

$>$ for minimizing the use of paper yet maximizing communication

3. Students learn to apply algebra, trigonometry and statistics in engineering problems.

4. Students learn to apply calculus in engineering problems.

5. Students learn about vectors, moments and truss loads for mechanical engineering and civil engineering problems.

6. Students learn to solve problems where force, mass, linear motion, angular motion and kinematics are applied.

7. Students learn to solve problems where work, power and energy are applied.

8. Students learn to solve electric circuit problems for both AC and DC circuits.

9. Students learn to make (MS) Powerpoint presentations to the class on the subject of famous engineers to familiarize themselves with role models in the various engineering disciplines. 
10. Students learn about the process for professional engineering (PE) licensing.

Upon completion of the Fundamentals course, students are very self-confident and are highly motivated to conquer the engineering courses they will be taking after Fundamentals.

Occasionally, I encounter juniors and seniors from the local engineering college, Florida Atlantic University, Boca Raton, Florida who have completed the Fundamentals course at PBSC. All students who have completed the course have commented that the course is very demanding but they feel that it has prepared them well for the higher level engineering courses.

References (primary resources):

1. Introduction to Engineering by Craver, Schroeder and Tarquin (Oxford University Press, NY, 1987) ISBN\# 0-19-510725-X

2. Schaum's Outline of Theory and Problems of Engineering Mechanics, Statics and Dynamics, Fifth Edition (McGraw-Hill Companies, 1998) ISBN 0-07-046193-7

3. Schaum's Outline of Theory and Problems of Electric Circuits, Fourth Edition (McGraw-Hill Companies, 2003) ISBN 0-07-139307-2

4. Web Site: Lessons in Electric Circuits: www.allaboutcircuits.com

5. Electricity: Principles and Applications by Richard J. Fowler, (Glencoe McGraw-Hill, NY, NY, Fifth Edition, 1999)

Commercial References:

- Microsoft Office, Microsoft Excel, Microsoft Word and Microsoft PowerPoint are software products of the Microsoft Corporation.

- MATLAB is a software product of Mathworks, Inc.

- Blackboard is an online educational network developed by Blackboard, Inc.

- Apple iPad is a microcomputer product of the Apple, Inc.

- OpenOffice is a software product of the Apache OpenOffice Foundation. 